Article

\title{
Discrete-Time Modeling of High Power Asymmetric Half-Bridge LED Constant-Current Driver Controlled by Digital Current Mode
}

\author{
Zhiyong Qiao ${ }^{1,2}$, Shunli Wang ${ }^{1,3, *}$, RongHai Wang ${ }^{2}$, Yile Shi ${ }^{1}$, Nan Zhang ${ }^{4}$, Zhigui Liu 1,* \\ 1 School of Information Engineering, Southwest University of Science and Technology, Mianyang 621010, \\ China; qzy5950998@163.com (Z.Q.); 435219655@qq.com (Y.S.) \\ 2 Department of Information Engineering, Mianyang Polytechnic, Mianyang 621000, China; wangronghai@ \\ mypt.edu.cn(R.W.) \\ 3 Department of Energy Technology, Aalborg University, Pontoppidanstraede 111, 9220 Aalborg East, \\ Denmark; dis@et.aau.dk \\ 4 Mianyang Maike Electronic Technology Co., Ltd., Mianyang 621000,China; zhangnan783.6@163.com \\ * Correspondence: wangshunli1985@126.com; Tel.: +86-15884655563 (S.W.); liuzhigui@swust.edu.cn; Tel.: \\ +86-13980125888 (Z.L.)
}

\begin{abstract}
The high-power Asymmetric half-bridge Converter (AHBC) LED constant current driver controlled by digital current mode is a fourth-order system. Static operating point, parasitic resistance, load characteristics, sampling effect, modulation mode and loop delay will have great influence on its dynamic performance. In this paper, the small-signal pulse transfer function of the driver is established by the discrete-time modeling method for the two operating points corresponding to the three modulation modes of the trailing edge, leading edge and double edge. And, the effects of parasitic parameters, delay effect, sampling effect and load effect are fully considered in modeling. For a large number of complex exponential matrix operations, the first order Taylor formula is used for approximate calculation after the coefficient matrix is obtained by substituting the data. Then, Matlab software is used to compare and analyze the discrete-time model and the discrete-average model. The results show that the proposed discrete-time model can more accurately characterize the resonant peak and high-frequency dynamic characteristics, and is very suitable for the design of high frequency digital controller.
\end{abstract}

Keywords: AHB LED constant-current driver; Digital Current-programmed control; discrete-time modeling; Modulation effect

\section{Introduction}

LED light source has many advantages such as high efficiency, energy saving, long life, high reliability and environmental friendliness, so it has been widely used in indoor and outdoor lighting. With the continuous improvement of luminous flux and luminous efficiency, it is expanding to high-power applications such as street lamps, squares, airports and stadiums in an all-round and rapid way[1-3]. As LED light source is usually driven by a constant current, the quality of driver will affect the overall performance of the light source. Asymmetric half-bridge converter has features of high conversion efficiency, low voltage stress, constant frequency control, and a small capacitive 
filter[4], it has great advantages when applied to high-power LED driver[5-8].

For AHBC, the feedback gain of current mode control can be increased independently of the secondary resonance to achieve better closed-loop performance.There are three Control modes including Peak Current Control (PCC)[9], Average Current Control (ACC)[10] and Charge Balance Control (CBC)[11]. Among them, Average Current mode Control is more conducive to the improvement of closed-loop performance of the converter[12]. Previous AHBC current mode control was mostly realized by analog method. Driven by the development trend of high frequency digitization, Dr. J.d. Van Wyk proposed the idea of full digital current mode control[13], which will be conducive to improving the anti-interference ability, power density and intelligence level of LED power supply.However, digital design will be faced with the problem that time quantization[14] and amplitude quantization[15] make the control performance worse. Therefore, the establishment of a more accurate small-signal discrete model will be beneficial to the improvement of digital control performance when parasitic parameters, modulation effects, quantization effects and loop delay are taken into account comprehensively[16].

For AHBC, J. Sebastan established its continuous small-signal model using the average circuit method[17]. This average model can accurately reflect the low frequency dynamic characteristics of the converter, but it has a large error in describing the high frequency characteristics above $3 \mathrm{kHz}$. Especially, the prediction of high frequency resonance peak is far from the actual measured value. Moreover, parasitic resistance has great influence on the dynamic performance. Since then, S. Abedinpour established the AHBC state-space averaging small-signal model for voltage mode control considering parasitic resistance[18]. B. Hoi established a state-space averaging small-signal model of the converter for current mode control AHBC, considering disturbance factors such as input voltage, primary side duty ratio, transformer leakage inductance and load current[19]. The state-space averaging small-signal model has been widely used in the design of analog controllers and has obtained better closed-loop control performance. Based on this model, the pulse transfer function of the converter can be obtained by using the mapping theory and considering the effects of sampling, modulation and delay[20]. However, the discrete-average model is not accurate enough to describe the dynamic characteristics of high frequency, and it can only adopt approximate method to handle the delay and quantization error, so the control performance is poor when it is used in the design of high frequency digital controller.

The discrete-time modeling aims at describing the dynamic characteristics of the sample waveforms of the converter. The piecewise concept was used to directly obtain the difference equation, and then the discrete small-signal model was obtained through linearization[21]. Discrete-time model can accurately describe the high-frequency dynamic characteristics of the converter and is very suitable for the design of digital compensation controller for high frequency DC-DC converter. The main research results include modeling for low sampling rate[22], for considering loop delay effect[23], and for considering sampling at any time point[24] etc.. For the problem that matrix exponential derivation is too complex in the process of discrete-time modeling, Taylor's first term is often used for approximate calculation[25]. In 2018, LI X built discrete-time models of Buck, Boost and Buck-Boost based on low-pass characteristics and considering modulation effect. Then, the model is transformed to S-domain for closed-loop design and better control effect is achieved[25]. For Buck LED driver controlled by peak current mode, Leng Minrui established an improved third-order discrete-time model. And, The stability analysis shows that the model is an effective and accurate small-signal model[27].

AHBC is a fourth-order system due to the existence of parasitic oscillation and output LC filter circuit. Due to a large number of complex matrix exponential calculations, it is difficult to obtain the symbolic expression of the discrete-time model even if the first order approximation is adopted. In this paper, the discrete-time modeling is used to model the AHBC LED constant-current driver controlled by digital current mode. In the process of modeling, parasitic parameters, modulation effects, sampling effects and load effects are considered comprehensively. The first order approximation is adopted to establish the discrete-time model corresponding to each static 
operation point directly into the data. Finally, comparative analysis will be carried out between the discrete-time model and the discrete-average model by Matlab software to verify the accuracy of the model.

\section{2. state-space description of AHBC LED constant-current driver}

Figure 1 shows the digital current mode control loop of AHBC LED constant-current driver. It is composed of inductance current inner loop and LED current outer loop, including AHBC, LED, digital PWM, sampling holder, $\mathrm{A} / \mathrm{D}$ converters and digital compensation. $R_{L E D}$ is the LED equivalent DC resistance at a specific operation point, which varies with operating point. $R_{C c}, R_{C f}$ and $R_{L f}$ are equivalent parasitic resistances of $C_{m}, L_{f}$ and $C_{f}$, while $R_{L s}$ and $R_{L E D s}$ are sampling resistances of inductance current and LED current respectively.

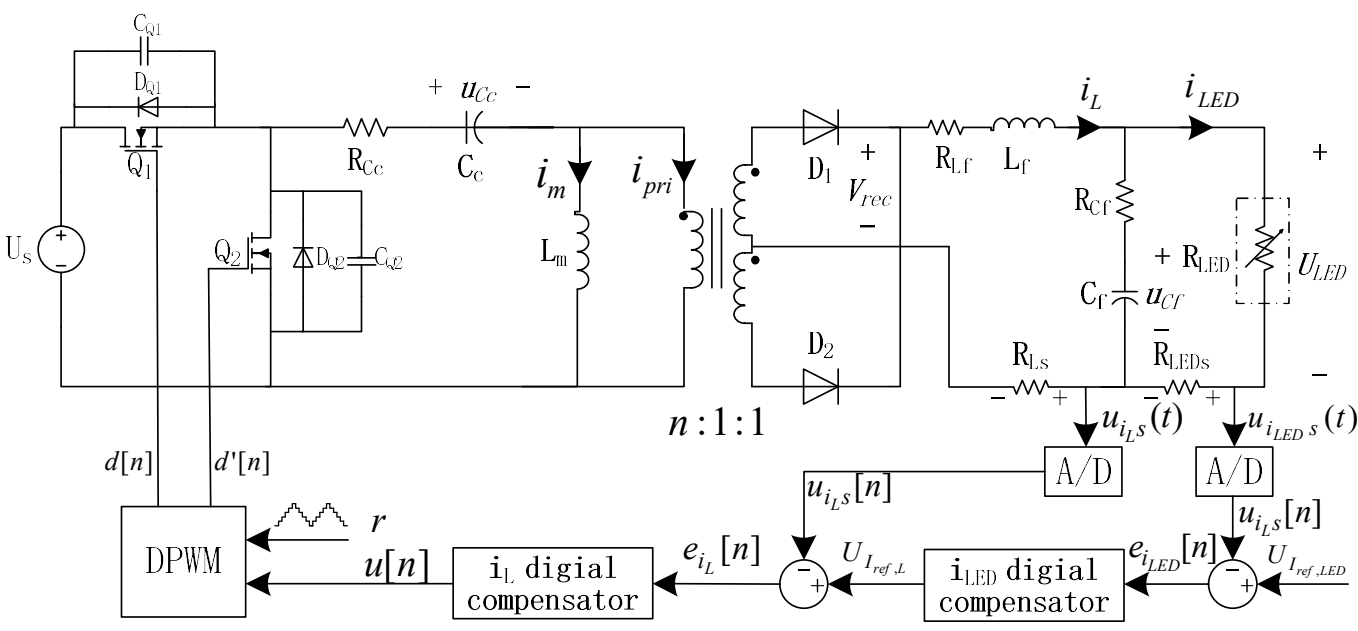

Figure 1. Block diagram of AHBC LED constant-current driver by digital current mode control.

The output of the $i_{L E D}$ digital compensator is taken as the given value of the inductor current, $U_{I_{r e f, L}}$. After $U_{I_{r e f, L}}$ is compared with the inductance current obtained by high-speed sampling, the control signal $u[n]$ of the DPWM is calculated by the $i_{L}$ digital controller, and then the duty ratio is adjusted to achieve the purpose of fast tracking the LED reference current. The outer loop is usually compensated by the digital PI regulator, and the inner loop can be controlled by the predictive current algorithm. The open-loop state-space description of AHBC LED constant-current driver without considering the control loop is shown in Equation (1).

$$
\left\{\begin{array}{l}
\dot{\mathbf{x}}=d\left[\mathbf{A}_{\mathbf{1}} \mathbf{x}+\mathbf{B}_{\mathbf{1}} \mathbf{u}_{\mathbf{s}}\right]+d^{\prime}\left[\mathbf{A}_{\mathbf{0}} \mathbf{x}+\mathbf{B}_{\mathbf{0}} \mathbf{u}_{s}\right] \\
\mathbf{y}=d\left[\mathbf{C}_{\mathbf{1}} \mathbf{x}+\mathbf{E}_{\mathbf{1}} \mathbf{u}_{\mathbf{s}}\right]+d^{\prime}\left[\mathbf{C}_{\mathbf{0}} \mathbf{x}+\mathbf{E}_{\mathbf{0}} \mathbf{u}_{s}\right]
\end{array}\right.
$$

Where, $\mathbf{x}=\left(\begin{array}{llll}u_{C c} & i_{p} & i_{L} & u_{C f}\end{array}\right)^{T}$ is the state variable, $\mathbf{y}=\left(\begin{array}{ll}i_{L} & i_{L E D}\end{array}\right)^{T}$ is the output vector, $\mathrm{U}$ is the input vector, $A_{i}, B_{i}, C_{i}$ and $E_{i}$ are the state-space model of the converter sub-topology, $i \in\{0,1\}$ is the operating state, $d$ and $d^{\prime}=1-d$ are the PWM continuous time control signal.The static operating point is shown in Equation (2). 


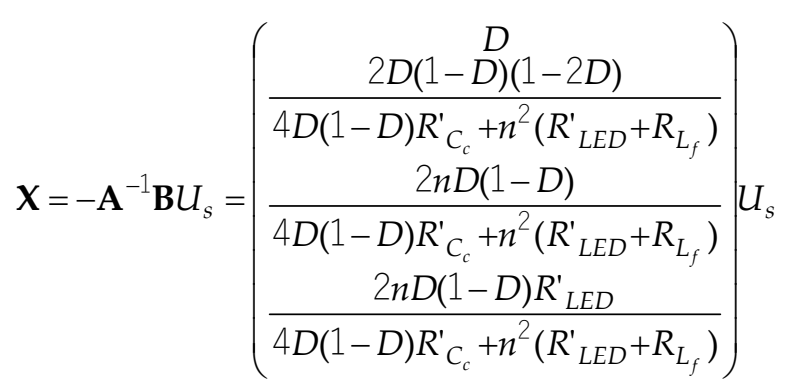

After adding the small-signal disturbance, removing the DC component and taking Laplace transform, the open-loop transfer function of state-space average small-signal from duty ratio to inductance current and LED current can be derived, as shown in Equation (3).

$$
\left\{\begin{array}{l}
G_{\hat{i}_{L} d}(s)=\frac{\hat{i}_{L}(s)}{\hat{d}(s)} \approx k_{i d} \frac{\left(1+s / \omega_{c r}\right)\left(1+s /\left(Q_{n 1} \omega_{n 1}\right)+s^{2} / \omega_{n 1}{ }^{2}\right)}{\left(1+s /\left(Q_{d 1} \omega_{d 1}\right)+s^{2} / \omega_{d 1}^{2}\right)\left(1+s / Q_{d 1} \omega_{d 1}+s^{2} / \omega_{d 1}^{2}\right)} \\
G_{\hat{i}_{L E D} d}(s)=\frac{\hat{i}_{L E D}(s)}{\hat{d}(s)} \approx k_{i d} \frac{\left(1+s / \omega_{e s r}\right)\left(1+s /\left(Q_{n 1} \omega_{n 1}\right)+s^{2} / \omega_{n 1}{ }^{2}\right)}{\left(1+s /\left(Q_{d 1} \omega_{d 1}\right)+s^{2} / \omega_{d 1}{ }^{2}\right)\left(1+s / Q_{d 1} \omega_{d 1}+s^{2} / \omega_{d 1}{ }^{2}\right)}
\end{array}\right.
$$

Where,

$$
\begin{aligned}
& k_{i d}=\frac{2(1-2 D) U_{s}}{n\left(R_{L E D}^{\prime}+R_{L_{f}}^{\prime}\right)} \\
& \omega_{e s r}=\frac{1}{R_{C_{f} C_{f}}}, \omega_{c r}=\frac{1}{\left(R_{L E D}^{\prime}+R_{C_{f}}\right) C_{f}}, \omega_{n 1}=\sqrt{\frac{2}{L_{m} C_{c}}}, \omega_{d 1}=\sqrt{\frac{1}{L_{f} C_{f}}}, \omega_{d 2}=\sqrt{\frac{1}{L_{m} C_{c}}} \\
& Q_{n 1}=\frac{1}{\frac{2 D(1-D) L m}{n^{2}\left(R_{L E D}^{\prime}+R_{L_{f}}^{\prime}\right)}+R_{C_{c}} C_{c}} \omega_{n 1}^{-1}, Q_{d 1}=\frac{R_{L E D}^{\prime}+R_{L_{f}}^{\prime}}{\left(R_{L E D}^{\prime} R_{L_{f}}^{\prime}+R_{L_{f}}^{\prime} R_{C_{f}}+R_{L E D}^{\prime} R_{C_{f}}\right) C_{f}+L_{f}} \omega_{d 1}{ }^{-1}, Q_{d 2}=\frac{1}{R_{C_{c}} C_{c}} \omega_{d 2^{-1}}
\end{aligned}
$$

This state-space average small-signal model fully considers the influence of parasitic parameters and load effect. It can well reflect the low-frequency dynamic characteristics of the converter. When it is applied to the design of the analog controller, a better control effect is achieved. However, sampling mode, loop delay, modulation effect and other factors are not taken into account in the establishment of the model, which is one of the main reasons for the deterioration of digital control performance.

\section{Discrete-time modeling of AHBC LED constant-current driver}

Without considering the small signal disturbance, the difference equation expression of static operating point of the converter is obtained by integrating equation (1), as shown in Equation (4).

$$
\left\{\begin{array}{l}
\mathbf{X}\left((n+1) T_{s}\right)=\left(I-e^{\mathbf{A}_{1} D T_{s}} e^{\mathbf{A}_{\mathbf{0}} D^{\prime} T_{s}}\right)^{-1}\left[-e^{\mathbf{A}_{1}\left(D T_{s}\right)} \mathbf{A}_{\mathbf{0}}^{-1}\left(\mathbf{I}-e^{\mathbf{A}_{0} D^{\prime} T_{s}}\right) \mathbf{B}_{\mathbf{0}}-\mathbf{A}_{1}^{-1}\left(\mathbf{I}-e^{\mathbf{A}_{1} D T_{s}}\right) \mathbf{B}_{1}\right] \mathbf{U}_{\mathbf{s}} \\
\mathbf{Y}\left((n+1) T_{s}\right)=\mathbf{C}\left(I-e^{\mathbf{A}_{1} D T_{s}} e^{\mathbf{A}_{\mathbf{0}} D^{\prime} T_{s}}\right)^{-1}\left[-e^{\mathbf{A}_{1}\left(D T_{s}\right)} \mathbf{A}_{\mathbf{0}}^{-1}\left(\mathbf{I}-e^{\mathbf{A}_{\mathbf{0}} D^{\prime} T_{s}}\right) \mathbf{B}_{\mathbf{0}}-\mathbf{A}_{1}^{-1}\left(\mathbf{I}-e^{\mathbf{A}_{1} D T_{s}}\right) \mathbf{B}_{1}\right] \mathbf{U}_{\mathbf{s}}+\mathbf{E} \mathbf{U}_{\mathbf{s}}
\end{array}\right.
$$

PWM modulation of DC-DC converter includes three modes: trailing-edge, leading-edge and double-edge. As shown in Figure 2, the modulator itself has inherent modulation delay. In addition, regular sampling is often used in digital control. For example, in the case of trailing-edge 
modulation, the output is synchronously sampled when the PWM output is at a low level, and the sampled value is kept and used for duty cycle control. The modulation delay and sampling delay will lead to the existence of loop delay, which will affect the stability and dynamics of the system.

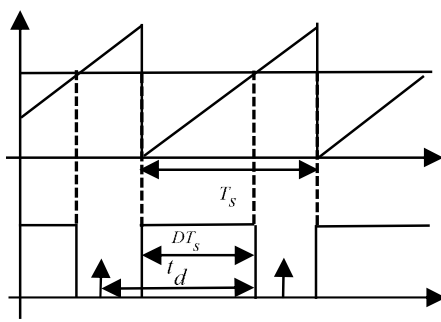

(a)

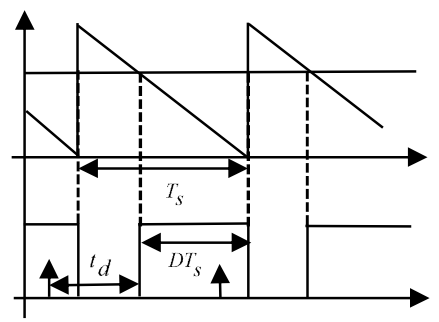

(b)

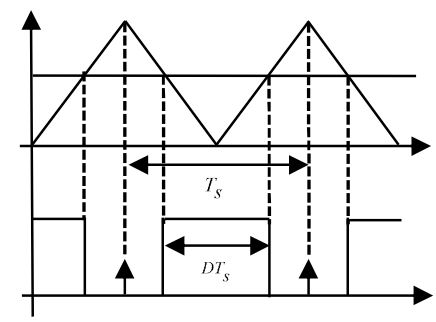

(c)

Figure 2. Modulation method: (a)Trailing-edge modulation; (b) Leading-edge modulation; (c) Double-edge modulation.

The Sequence diagram and waveform of AHBC with trailing-edge modulation are shown in Figure 3. Sampling is carried out during $D=0$, and $n t_{\text {sampl }} \sim(n+1) t_{\text {sampl }}$ is taken as the switching period to Discrete-time modeling. Where, $t_{\text {sampl }}$ is the sampling time point and $t_{d}$ is the delay time including sampling delay $t_{d s}$, calculated delay $t_{d c}$ and modulation delay $t_{d m}, \hat{d}_{n}$ is the small duty cycle signal disturbance, and $\mathbf{x}(n)$ is the state variable.

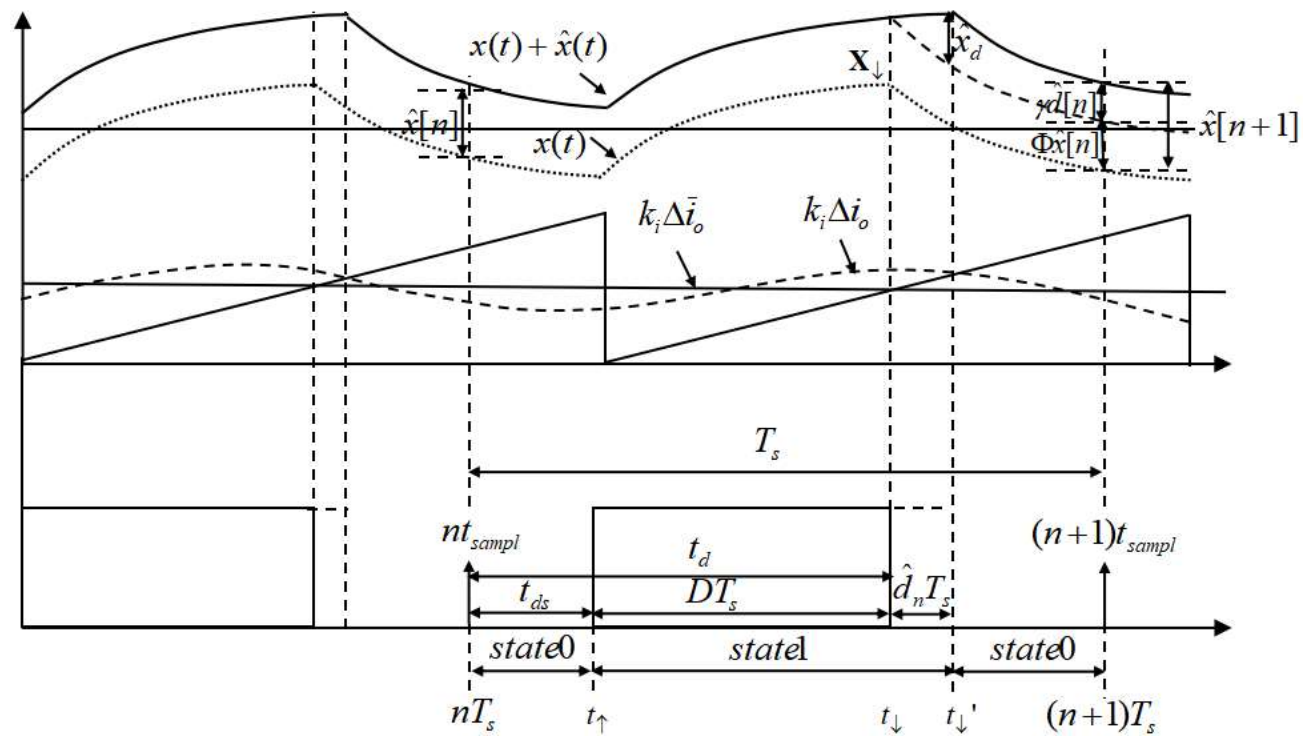

Figure 3. Sequence diagram and waveform of $\mathrm{AHBC}$ with trailing-edge modulation

For trailing-edge modulation, when small-signal disturbance is added, DC component is removed and the state-space equation is integrated in the interval of $n T_{s} \sim n T_{s}+t_{d}-D T_{s}$, $n T_{s}+t_{d}-D T_{s} \sim n T_{s}+t_{d}+\hat{d}_{n} T_{s}$ and $n T_{s}+t_{d}-D T_{s} \sim n T_{s}+t_{d}+\hat{d}_{n} T_{s}$ respectively, the specific expression of the small-signal discrete-time model can be obtained as shown in Table 1. 
Table 1. Discrete-time modeling of AHBC with trailing-edge modulation

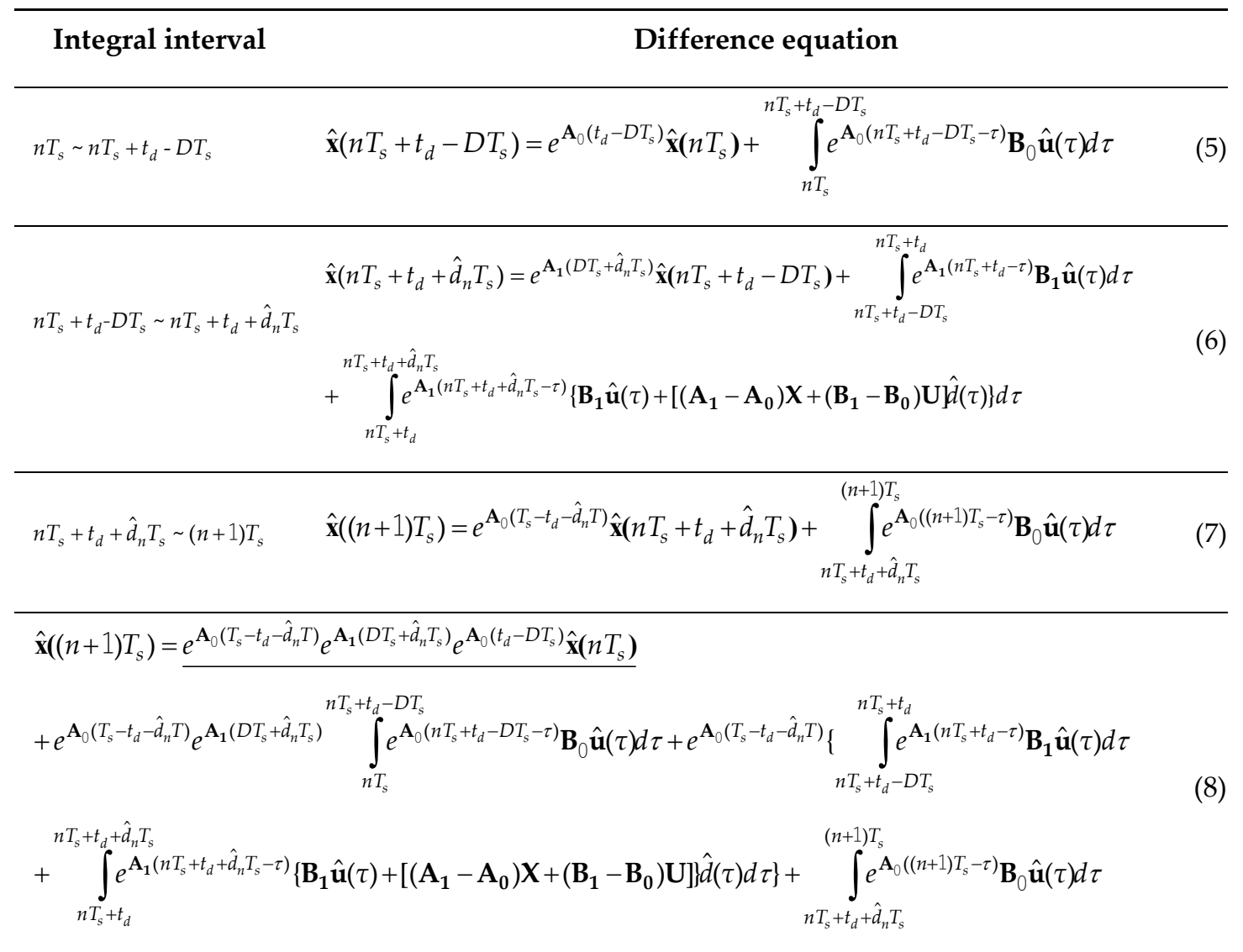

For Formula (8), assuming no input disturbance, i.e. $\hat{u}=0$, the difference equation of converter as shown in Equation (9) can be obtained.

$$
\left\{\begin{array}{l}
\hat{\mathbf{x}}[n+1]=\Phi \hat{\mathbf{x}}[n]+\gamma \hat{d}[n] \\
\hat{\mathbf{y}}[n+1]=\delta \hat{\mathbf{x}}[n+1]
\end{array}\right.
$$

Table 2 shows the coefficient matrix of the difference equation with modulation of Trailing-edge, Leading-edge and Double-edge respectively.

Table 2. Small-signal Discrete-time models corresponding to different modulation modes

\begin{tabular}{lll}
\hline Trailing-edge modulation & Leading-edge modulation & Double-edge modulation \\
\hline$\Phi=e^{\mathbf{A}_{0}\left(T_{s}-t_{d}\right)} e^{\mathbf{A}_{1} D T_{s}} e^{\mathbf{A}_{0}\left(t_{d}-D T_{s}\right)}$ & $\Phi=e^{\mathbf{A}_{1}\left(t_{d}-D^{\prime} T_{s}\right)} e^{\mathbf{A}_{0} D^{\prime} T_{s}} e^{\mathbf{A}_{1}\left(T_{s}-t_{d}\right)}$ & $\Phi=e^{\mathbf{A}_{0} \frac{T_{s}}{2}(1-D)} e^{\mathbf{A}_{1}\left(D T_{s}\right)} e^{\mathbf{A}_{0} \frac{T_{s}}{2}(1-D)}$ \\
$\gamma=T_{s} e^{\mathbf{A}_{0}\left(T_{s}-t_{d}\right)} F_{\downarrow}$ & $\gamma=T_{s} e^{\mathbf{A}_{0}\left(T_{s}-t_{d}\right)} F_{\uparrow}$ & $\gamma=\frac{T_{s}}{2} e^{\mathbf{A}_{0} \frac{T_{s}}{2}(1-D)}\left(F_{\downarrow}+e^{\mathbf{A}_{1} D T_{s}} F_{\uparrow}\right)$ \\
$\delta=C_{0}$ & $\delta=C_{1}$ & $\delta=C_{0}$ \\
\hline
\end{tabular}




$$
\begin{aligned}
& F_{\downarrow}=\left[\left(\mathbf{A}_{\mathbf{1}}-\mathbf{A}_{0}\right) \mathbf{X}_{\downarrow}+\left(\mathbf{B}_{\mathbf{1}}-\mathbf{B}_{0}\right) \mathbf{U}\right] \\
& F_{\uparrow}=\left[\left(\mathbf{A}_{\mathbf{1}}-\mathbf{A}_{0}\right) \mathbf{X}_{\uparrow}+\left(\mathbf{B}_{\mathbf{1}}-\mathbf{B}_{0}\right) \mathbf{U}\right] \\
& \mathbf{X}_{\downarrow}=\left(\mathbf{I}-e^{\mathbf{A}_{\mathbf{1}} D T_{s}} e^{\mathbf{A}_{\mathbf{0}} D^{\prime} T_{s}}\right)^{-1}\left[-e^{\mathbf{A}_{\mathbf{1}} D T_{s}} \mathbf{A}_{\mathbf{0}}{ }^{-1}\left(I-e^{\mathbf{A}_{\mathbf{0}} D^{\prime} T_{s}}\right) \mathbf{B}_{\mathbf{0}}-\mathbf{A}_{\mathbf{1}}{ }^{-1}\left(\mathbf{I}-e^{\mathbf{A}_{\mathbf{1}} D T_{s}}\right) \mathbf{B}_{\mathbf{1}}\right] \mathbf{U} \\
& \mathbf{X}_{\uparrow}=e^{\mathbf{A}_{0}\left(D^{\prime} T_{s}\right)} \mathbf{X}_{\downarrow}-\mathbf{A}_{\mathbf{0}}{ }^{-1}\left(I-e^{\mathbf{A}_{\mathbf{0}} D^{\prime} T_{s}}\right) \mathbf{B}_{\mathbf{0}} \mathbf{U}
\end{aligned}
$$

After taking $\mathrm{z}$ transformation of Equation (9), the open-loop pulse transfer function shown in Formula (10) can be derived.

$$
W(z)=\frac{\hat{\mathbf{y}}(z)}{\hat{d}(z)}=\left[\begin{array}{l}
G_{i d}(z)=\frac{\hat{i}_{L}(z)}{\hat{d}(z)} \\
G_{u d}(z)=\frac{\hat{i}_{L E D}(z)}{\hat{d}(z)}
\end{array}\right]=\mathbf{C}_{0}(z I-\Phi)^{-1} \gamma
$$

Sampling, delay, modulation and other influencing factors are taken into full account when the pulse transfer function is established by the discrete-time modeling method. Theoretically, the small-signal discrete-time model can accurately represent the dynamic characteristics of the converter. However, to obtain the symbolic expression of the transfer function, a large number of complex matrix exponential operations are needed, and first-order Taylor expansion formula is often used for approximate calculation, as shown in Equation (11). But even so, for fourth-order systems, it is difficult to calculate the specific symbolic expression of the impulse transfer function, which is very inconvenient to analyze the relationship between converter parameters and system performance.

$$
e^{A T} \approx I-A T
$$

\section{Matlab simulation verification of the discrete-time model}

\subsection{AHBC LED constant current driver parameter design and its pulse transfer function}

The driver is powered by $220 \mathrm{~V} / 50 \mathrm{~Hz}$ AC, which is converted into $400 \mathrm{~V}( \pm 20 \%)$ DC by rectification and Boost PFC as the input of AHBC LED constant current driver. The hybrid module composed of $3 \times 14$ LEDs is selected as the load. The LED is XP-G2 R5 from CREE. The total power of the module is $210 \mathrm{~W}$. Considering the total output current of the constant-current driver, the performance of the discrete-time model is analyzed, and the following assumptions are made:

- Each switching device is an ideal device without considering the parasitic parameters of MOSFET and diode.

- All LEDs are ideal components with the same parameters, regardless of the effect of temperature, the LED module is equivalent with adjustable resistance.

Considering practical application needs, constant current driver is selected to work in two states. First, when the minimum input voltage is $325 \mathrm{~V}$, the full-load output current is $4.5 \mathrm{~A}$, and the output voltage is $48 \mathrm{~V}$. Secondly, when the highest input voltage is $445 \mathrm{~V}$, the lowest output current is $0.75 \mathrm{~A}$ and the output voltage is $37 \mathrm{~V}$. Operating condition, circuit component, and static operating points are shown in Table 3. Where, the static operating points are calculated by Formula (2). 
Table 3. Component parameters

\begin{tabular}{cl}
\hline \multicolumn{1}{c}{ Item } & \multicolumn{1}{c}{ parameters } \\
\hline \multirow{2}{*}{ Operating point 2} & $U_{s}=445 \mathrm{~V}, U_{L E D}=37 \mathrm{~V}, I_{L E D}=0.75 \mathrm{~A}, R_{L E D}=49.333 \Omega, D=0.147$, \\
& $U_{C c}=65.415 \mathrm{~V}, I_{m}=0.177 \mathrm{~A}, I_{L}=0.75 \mathrm{~A}, U_{C f}=37.052 \mathrm{~V}$ \\
\hline \multirow{2}{*}{ Operating condition } & $U_{s}=325 \sim 445 \mathrm{~V}, \mathrm{I}_{L E D}=0.75 \sim 4.5 \mathrm{~A}, U_{L E D}=37 \sim 48 \mathrm{~V}, n=3, T_{J}=85^{\circ} \mathrm{C}$, \\
& $R_{L E D}=49.333 \sim 10.667 \Omega, f_{s}=200 \mathrm{kHz}, T_{s}=5 \times 10^{-6} s, u_{r \max }=5 \mathrm{~V}$ \\
\hline \multirow{2}{*}{ Circuit component } & $C_{c}=0.12 \mu F\left(R_{C c}=1.327 \Omega\right), L_{m}=23.7 \mu \mathrm{H}, L_{f}=88 \mu \mathrm{H}\left(R_{L f}=0.12 \Omega\right)$, \\
& $C_{f}=66 \mu F\left(R_{C f}=0.002 \Omega\right), R_{L S}=R_{L E D s}=0.01 \Omega$ \\
\hline \multirow{2}{*}{ Operating point 1} & $U_{s}=325 \mathrm{~V}, U_{L E D}=48 \mathrm{~V}, I_{L E D}=4.5 \mathrm{~A}, R_{L E D}=10.667 \Omega$, \\
& $D=0.348, U_{C c}=113.1 \mathrm{~V}, I_{m}=0.456 \mathrm{~A}, I_{L}=4.5 \mathrm{~A}, U_{C f}=48 \mathrm{~V}$
\end{tabular}

By replacing component parameters, operating conditions and static operating points with Equation (3), the state-space average small-signal open-loop transfer function from duty ratio to inductance current and LED current corresponding to the two static working points can be obtained respectively, as shown in Table 4.

Table 4. State average small-signal model

\begin{tabular}{|c|c|}
\hline $\begin{array}{c}\text { Operating } \\
\text { point }\end{array}$ & State average small-signal model \\
\hline $\begin{array}{l}\text { Operating } \\
\text { point } 1 \\
(48 \mathrm{~V} / 4.5 \mathrm{~A})\end{array}$ & $\begin{array}{l}G_{i_{L} d 1}(s)=\frac{\hat{i}_{L}(s)}{\hat{d}(s)}=\frac{5.9559\left(7.0472 \times 10^{-4} s+1\right)\left(1.4421 \times 10^{-12} s^{2}+2.7418 \times 10^{-7} s+1\right)}{\left(5.6948 \times 10^{-9} s^{2}+2.5461 \times 10^{-5} s+1\right)\left(2.8361 \times 10^{-12} s^{2}+1.6347 \times 10^{-7} s+1\right)} \\
G_{i_{L E D} d 1}(s)=\frac{\hat{i}_{L E D}(s)}{\hat{d}(s)}=\frac{5.9564\left(7.9177 \times 10^{-7} s+1\right)\left(1.4421 \times 10^{-12} s^{2}+2.7418 \times 10^{-7} s+1\right)}{\left(5.6948 \times 10^{-9} s^{2}+2.5461 \times 10^{-5} s+1\right)\left(2.8361 \times 10^{-12} s^{2}+1.6347 \times 10^{-7} s+1\right)}\end{array}$ \\
\hline $\begin{array}{c}\text { Operating } \\
\text { point } 2 \\
(37 \mathrm{~V} / 0.75 \mathrm{~A})\end{array}$ & $\begin{array}{l}G_{i_{L} d 2}(s)=\frac{\hat{i}_{L}(s)}{\hat{d}(s)}=\frac{4.2217\left(3.3 \times 10^{-3} s+1\right)\left(1.4421 \times 10^{-12} s^{2}+1.7676 \times 10^{-7} s+1\right)}{\left(5.872 \times 10^{-9} s^{2}+1.5473 \times 10^{-5} s+1\right)\left(2.8019 \times 10^{-12} s^{2}+1.6352 \times 10^{-7} s+1\right)} \\
G_{i_{L E D} d 2}(s)=\frac{\hat{i}_{L E D}(s)}{\hat{d}(s)}=\frac{4.2224\left(7.9177 \times 10^{-7} s+1\right)\left(1.4421 \times 10^{-12} s^{2}+1.7676 \times 10^{-7} s+1\right)}{\left(5.872 \times 10^{-9} s^{2}+1.5473 \times 10^{-5} s+1\right)\left(2.8019 \times 10^{-12} s^{2}+1.6352 \times 10^{-7} s+1\right)}\end{array}$ \\
\hline $\begin{array}{l}\text { In order } \\
\text { function is ob } \\
C_{0}, C_{1}, E_{0} \\
\Phi \text { and } \gamma \text { is } \\
\text { calculated. F } \\
\text { discrete-time } \\
\text { and LED cur }\end{array}$ & $\begin{array}{l}\text { simplify the calculation of exponential matrix, the discrete time small signal transfer } \\
\text { ined in three steps. First, the values of coefficient matrices such as } A_{0}, A_{1}, B_{0}, B_{1} \text {, } \\
E_{1} \text { are calculated by substituting the parameters. Then, the exponential matrix in } \\
\text { placed by the first-order Taylor expansion shown in Formula (11), and the values are } \\
\text { ally, put the calculated } \Phi \text { and } \gamma \text { values into Formula (10) to obtain the } \\
\text { hall-signals open-loop pulse transfer functions from duty ratio to inductance current } \\
\text { nt corresponding to the two static working points in three modulation modes } \\
\text { shown in Table 5. }\end{array}$ \\
\hline
\end{tabular}


Table 5. small-signal discrete-time models corresponding to the three modes of modulation

\begin{tabular}{|c|c|c|}
\hline Modulation & Operating point & Discrete-time model \\
\hline \multirow{4}{*}{$\begin{array}{l}\text { Trailing-edge } \\
\text { modulation }\end{array}$} & operating point 1 & $G_{i_{L} d T 1}(z)=\frac{\hat{i}_{L}(z)}{\hat{d}(z)}=\frac{4.2667(z+3.686)(z+1.204)(z-0.9934)}{\left(z^{2}-2.015 z+1.019\right)\left(z^{2}+3.737 z+6.752\right)}$ \\
\hline & $\left(t_{d}=3 \mu s\right)$ & $G_{i_{L E D} d T 1}(z)=\frac{\hat{i}_{L E D}(z)}{\hat{d}(z)}=\frac{0.012817(z+0.075)\left(z^{2}+5.439 z+16.03\right)}{\left(z^{2}-2.015 z+1.019\right)\left(z^{2}+3.737 z+6.752\right)}$ \\
\hline & operating point 1 & $G_{i_{L} d T 2}(z)=\frac{\hat{i}_{L}(z)}{\hat{d}(z)}=\frac{7.7993(z+5.744)(z+1.419)(z-0.9993)}{\left(z^{2}-1.998 z+1.002\right)\left(z^{2}+3.004 z+7.01\right)}$ \\
\hline & $\left(t_{d}=2 \mu s\right)$ & $G_{i_{L E D} d T 2}(z)=\frac{\hat{i}_{L E D}(z)}{\hat{d}(z)}=\frac{0.0075702(z+0.1403)\left(z^{2}+5.211 z+16.33\right)}{\left(z^{2}-1.998 z+1.002\right)\left(z^{2}+3.004 z+7.01\right)}$ \\
\hline \multirow{4}{*}{$\begin{array}{l}\text { Leading-edge } \\
\text { modulation }\end{array}$} & operating point 1 & $G_{i_{L} d L 1}(z)=\frac{\hat{i}_{L}(z)}{\hat{d}(z)}=\frac{0.70845(z-0.9914)\left(z^{2}+12.45 z+41.44\right)}{\left(z^{2}-2.013 z+1.017\right)\left(z^{2}+2.568 z+6.8\right)}$ \\
\hline & $\left(t_{d}=4 \mu s\right)$ & $G_{i_{L E D} d L 1}(z)=\frac{\hat{i}_{L E D}(z)}{\hat{d}(z)}=\frac{0.00081723(z+13.2)\left(z^{2}+3.767 z+19.14\right)}{\left(z^{2}-2.013 z+1.017\right)\left(z^{2}+2.568 z+6.8\right)}$ \\
\hline & operating point 2 & $G_{i_{L} d L 2}(z)=\frac{\hat{i}_{L}(z)}{\hat{d}(z)}=\frac{4.8927(z-0.9979)\left(z^{2}+2.558 z+17.34\right)}{\left(z^{2}-1.998 z+1.002\right)\left(z^{2}+0.488 z+7.766\right)}$ \\
\hline & $\left(t_{d}=4.5 \mu s\right)$ & $G_{i_{L E D} d L 2}(z)=\frac{\hat{i}_{L E D}(z)}{\hat{d}(z)}=\frac{0.001904(z+3.626)\left(z^{2}+0.9309 z+15.91\right)}{\left(z^{2}-1.998 z+1.002\right)\left(z^{2}+0.488 z+7.766\right)}$ \\
\hline \multirow{4}{*}{$\begin{array}{l}\text { Double-edge } \\
\text { modulation }\end{array}$} & operating point 1 & $G_{i_{L} d D 1}(z)=\frac{\hat{i}_{L}(z)}{\hat{d}(z)}=\frac{4.9578(z-0.9932)\left(z^{2}+3.825 z+3.962\right)}{\left(z^{2}-2.015 z+1.019\right)\left(z^{2}+3.821 z+6.722\right)}$ \\
\hline & $\left(t_{d}=2.5 \mu s\right)$ & $G_{i_{L E D} d D 1}(z)=\frac{\hat{i}_{L E D}(z)}{\hat{d}(z)}=\frac{0.0074818(z+0.1306)\left(z^{2}+9.969 z+25.28\right)}{\left(z^{2}-2.015 z+1.019\right)\left(z^{2}+3.821 z+6.722\right)}$ \\
\hline & operating point 2 & $G_{i_{L} d D 2}(z)=\frac{\hat{i}_{L}(z)}{\hat{d}(z)}=\frac{8.6519(z+4.047)(z+2.125)(z-0.9989)}{\left(z^{2}-1.998 z+1.002\right)\left(z^{2}+3.514 z+7.252\right)}$ \\
\hline & $\left(t_{d}=2.5 \mu s\right)$ & $G_{i_{L E D} d D 2}(z)=\frac{\hat{i}_{L E D}(z)}{\hat{d}(z)}=\frac{0.0060451(z+0.3109)\left(z^{2}+6.84 z+18.53\right)}{\left(z^{2}-1.998 z+1.002\right)\left(z^{2}+3.514 z+7.252\right)}$ \\
\hline
\end{tabular}

\subsection{Matlab simulation analysis of the discrete-time model}

Bode Diagram comparison of discrete-average model and discrete-time model is shown in Figure 4 to Figure 6, where, the discrete-average models are obtained by discretizing the state-average small-signal open-loop transfer functions. In the figures, Ld and LEDd represent the transfer function from duty ratio to inductance current and to LED current respectively. $S$ represents the discrete average model, while $\mathrm{T}, \mathrm{L}$ and $\mathrm{D}$ represent the discrete-time models corresponding to the Trailing-edge, Leading-edge and Double-edge modulation respectively. 1 and 2 represent two types of operation states. 


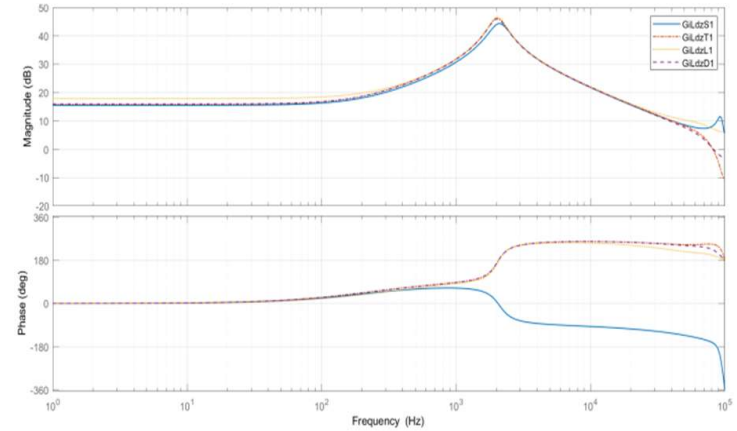

(a)

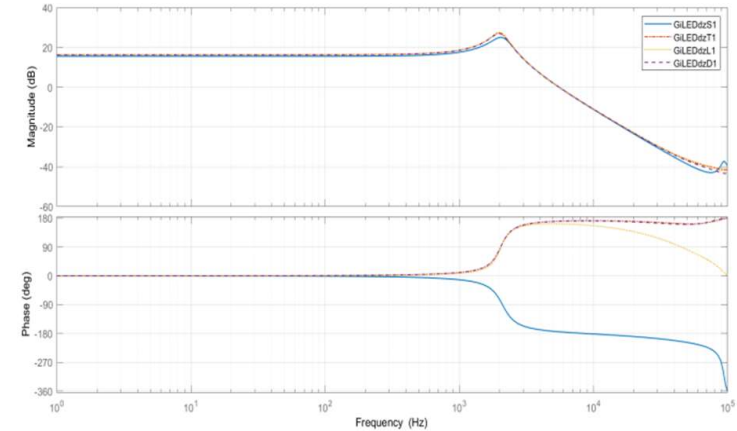

(b)

Figure 4. Bode Diagram comparison of discrete-time model and discrete-average model at the point of $325 \mathrm{~V}$ input and $4.5 \mathrm{~A} / 48 \mathrm{~V}$ output: (a)transfer function from duty ratio to inductive current; (b)transfer function from duty ratio to LED current.

Figure 4 shows the Bode diagram of the discrete-average model and the discrete-time model when output is $4.5 \mathrm{~A} / 48 \mathrm{~V}$. It can be seen that the amplitude-frequency characteristics of the discrete-time model and the discrete-average model deviate significantly at the resonance peak and after $50 \mathrm{kHz}$. This further indicates that the state-space small signal model is not accurate enough to characterize the resonance peak and high-frequency band. In addition, compared with Trailing-edge and Double-edge modulation, when the AHBC is modulated by Leading-edge, the amplitude of inductance current has a large deviation in the low frequency band and the phase of LED current has a larger lag in the high frequency band.

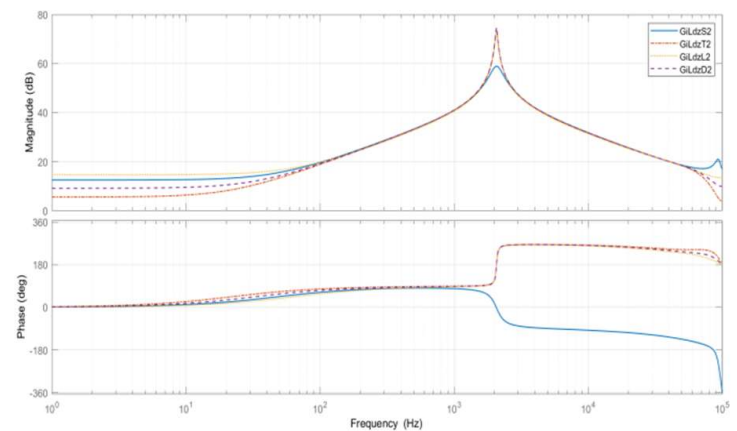

(a)

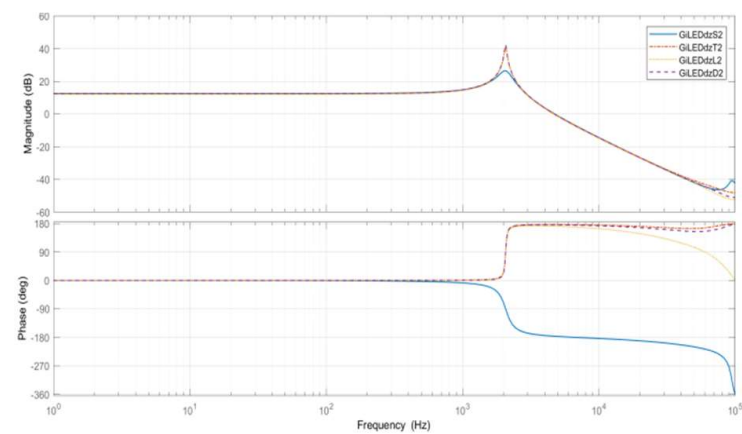

(b)

Figure 5. Bode Diagram comparison of discrete-time model and discrete-average model at the point of $445 \mathrm{~V}$ input and $0.75 \mathrm{~A} / 37 \mathrm{~V}$ output: (a)transfer function from duty ratio to inductive current; (b)transfer function from duty ratio to LED current.

Figure 5 shows the Bode diagram of the discrete-average model and the discrete-time model when output is $0.75 \mathrm{~A} / 37 \mathrm{~V}$. It can be seen that under light load, the amplitude-frequency characteristics of the inductance current also have a large deviation in the low-frequency component under the three modes of modulation, except for the great difference between the resonant peak and the high frequency. However, it can also be seen that the discrete time model is very accurate in describing the dynamic characteristics of LED current. 


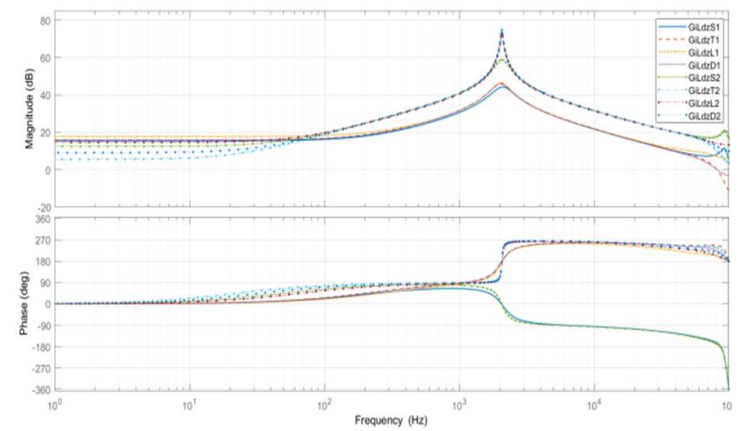

(a)

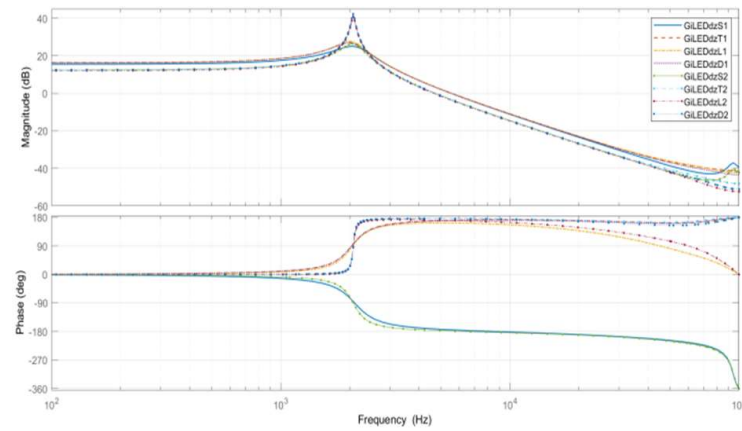

(b)

Figure 6. Bode Diagram comparison of state 1 and state 2: (a)transfer function from duty ratio to inductive current; (b)transfer function from duty ratio to LED current.

As can be seen from Figure 6, compared with full load, amplitude-frequency characteristics are different in the whole frequency band when output is under light load, and the resonance peak value obviously increases. This shows the influence of static operation point on small-signal dynamic models.

Figure 7 shows the root locus of the discrete model corresponding to state 1 . Where, (a) to (d), (e) to $(\mathrm{h})$ are discrete models of duty ratio to inductance current and duty ratio to LED current respectively. (a) and (e) are based on the state-space average method, but (b) to (d) and (f) to (h) are respectively based on the discrete-time modeling in three modulation modes. It can be seen that the impulse transfer function established by the discrete-time modeling is no longer stable because the loop delay is taken into account. This further confirms the effect of delay on the stability of the open-loop system.

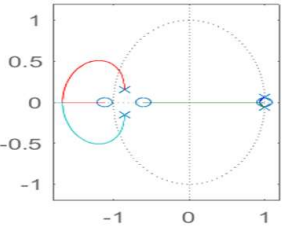

(a)

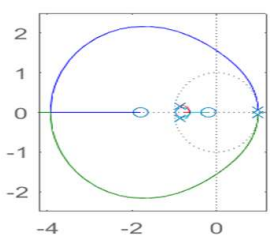

(e)

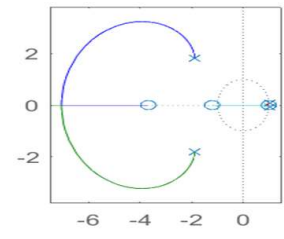

(b)

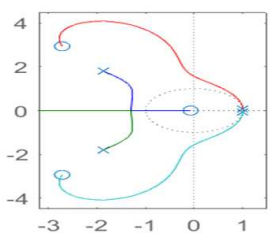

(f)

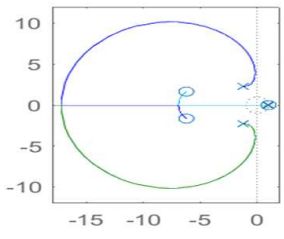

(c)

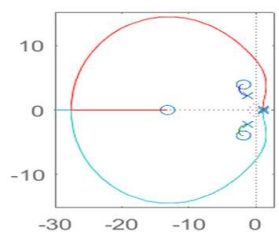

(g)

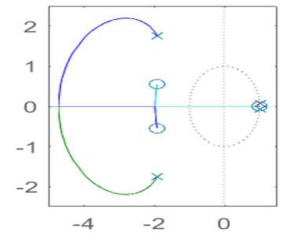

(d)

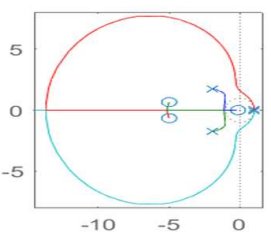

(h)

Figure 7. Root locus comparison of state 1: (a) to (d) are transfer functions from duty ratio to inductive current; (e) to (h) are transfer functions from duty ratio to LED current; (a) and (e) are based on the state-space average method; (b) to (d) and (f) to (h) are respectively based on the discrete-time modeling in three modulation modes.

\section{Conclusions}

In this paper, the discrete-time small-signal model at different operating points and input conditions was established for AHBC LED constant current driver with Trailing-edge, Leading-edge and Double-edge modulation. The effects of parasitic resistance, load characteristics, sampling effect, 
modulation effect and loop delay were considered. The complex matrix exponential operation was calculated by first order approximation and directly substituted into the data. The results show that the proposed discrete-time model can more accurately characterize the resonant peak and high-frequency dynamic characteristics, and is very suitable for the design of high-frequency digital controller.

Author Contributions: Conceptualization, S.W. and Z.L.; resources, R.W.; Data curation N.Z.; Formal analysis and Writing - original draft, Z.Q.; Writing - review and editing, Y.S. All authors have read and agreed to the published version of the manuscript.

Funding: National Natural Science Foundation of China (No. 61801407); Applied Basic Research Programs of Sichuan Science and Technology Department, China (No. 2018JY0337).

Acknowledgments: The work was supported by the National Natural Science Foundation of China (No. 61801407) and Applied Basic Research Programs of Sichuan Science and Technology Department, China (No. 2018JY0337).

Conflicts of Interest: The authors declare that there are no conflicts of interest regarding the publication of this paper.

\section{References}

1. Ramakrishnareddy Ch, K.; Porpandiselvi, S.; Vishwanathan, N., An efficient ripple-free LED driver with zero-voltage switching for street lighting applications. Epe J 2019, 29, (3), 120-131.

2. Bhardwaj, J.; Cesaratto, J.M.; Wildeson, I.H.; Choy, H.; Tandon, A., Progress in high-luminance LED technology for solid-state lighting. physica status solidi (a) 2017, 214, (8), 1600826.

3. Fang, P.; Webb, S.; Chen, Y.; Liu, Y.; Sen, P.C., A Multiplexing Ripple Cancellation LED Driver With True Single-Stage Power Conversion and Flicker-Free Operation. Ieee T Power Electr 2019, 34, (10), 10105-10120.

4. Huang, Y.; Li, C.; Chen, Y., A Modified Asymmetrical Half-Bridge Flyback Converter for Step-Down AC-DC Applications. Ieee T Power Electr 2020, 35, (5), 4613-4621.

5. Ting, C.; Hsu, Y.; Lin, J.; Chen, C., A Single-Stage Asymmetrical Half-Bridge Flyback Converter with Resonant Operation. Energies (Basel) 2018, 11, (7), 1721.

6. Kathiresan, R.; Das, P.; Reindl, T.; Panda, S.K., A Novel High-Power Nonresonant Multichannel LED Driver. Ieee T Ind Electron 2017, 64, (7), 5851-5864.

7. Mujjalinvimut, E.; Ayudhya, P.; Sangswang, A., An Improved Asymmetrical Half-Bridge Converter with Self-Driven Synchronous Rectifier for Dimmable LED Lighting. Ieee T Ind Electron 2016, 63, (2), 913-925.

8. Arias; Manuel; Lamar; Diego; G., Digital Implementation of the Feedforward Loop of the Asymmetrical Half-Bridge Converter for LED Lighting Applications. Ieee J Em Sel Top P 2015, 3, (3), 642-653.

9. Zhang, X.; Min, R.; Lyu, D.; Zhang, D.; Wang, Y., Current tracking delay effect minimization for digital peak current mode control of DC-DC boost converter. Ieee T Power Electr 2019, 1-10.

10. Qiu, Y.; Liu, H.; Chen, X., Digital Average Current-Mode Control of PWM DC-DC Converters Without Current Sensors. Ieee T Ind Electron 2010, 57, (5), 1670-1677.

11. Meyer, E.; Liu, Y.F., Digital Charge Balance Controller With an Auxiliary Circuit for Improved Unloading Transient Performance of Buck Converters. Ieee T Power Electr 2013, 28, (1), 357-370.

12. Choi, B.; Lim, W.; Choi, S.; Jian, S., Comparative Performance Evaluation of Current-Mode Control Schemes Adapted to Asymmetrically Driven Bridge-Type Pulsewidth Modulated DC-to-DC Converters. Ieee T Ind Electron 2008, 55, (5), 2033-2042.

13. van Wyk, J.D.; Lee, F.C., On a Future for Power Electronics. Ieee J Em Sel Top P 2013, 1, (2), 59-72. 
14. Sype, D.; Gussemé, K.D.; Bossche, A.; Melkebeek, J.A., Small-signal Laplace-domain analysis of uniformly-sampled pulse-width modulators. 2004, 6, 4292-4298 Vol.6.

15. Peterchev, A.V.; Sanders, S.R., Quantization resolution and limit cycling in digitally controlled PWM converters. Ieee T Power Electr 2003, 18, (1), 301-308.

16. Maksimovic, D.; Zane, R., Small-Signal Discrete-Time Modeling of Digitally Controlled PWM Converters. Ieee T Power Electr 2007, 22, (6), 2552-2556.

17. Sebastian, J.; Cobos, J.A.; Garcia, O.; Uceda, J., In Small-signal modelling of the half-bridge complementary-control DC-to-DC converter, IV IEEE International Power Electronics Congress, San Luis Potosi, 1995, 1995; IEEE: San Luis Potosi, 1995; pp. 44-50.

18. Abedinpour, S.; Liu, R.; Fasullo, G.; Shenai, K., In Small-signal analysis of a new asymmetrical half-bridge DC-DC converter, 2000 IEEE 31st Annual Power Electronics Specialists Conference, Galway, 2000, 2000; IEEE: Galway, 2000; pp. 843-847 vol.2.

19. Choi, B.; Lim, W.; Bang, S.; Choi, S., Small-signal analysis and control design of asymmetrical half-bridge DC-DC converters. Ieee T Ind Electron 2006, 53, (2), 511-520.

20. Yao, L.; Abu-Qahouq, J.A.; Batarseh, I., In Unified analog and digital models for half bridge DC-DC converter with current doubler rectifier, 2005, 2005; IEEE: 2005; pp. 1386-1392 Vol. 3.

21. Packard, D.J. Discrete modeling and analysis of switching regulators.California Institute of Technology, Pasadena, 1976.

22. Huliehel, F.; Ben-Yaakov, S., Low-frequency sampled-data models of switched mode DC-DC converters. Ieee T Power Electr 1991, 6, (1), 55-61.

23. Maksimovic, D.; Zane, R., Small-signal Discrete-time Modeling of Digitally Controlled DC-DC Converters. Ieee Workshops on Computers in Power Electronics 2006, 231-235.

24. Van, D.; Gusseme, K.D.; Van, D.; Melkebeek, J.A., Small-signal z-domain analysis of digitally controlled converters. Ieee T Power Electr 2006, 21, (2), 470-478.

25. Rajasekaran, V.; Jian, S.; Heck, B.S., Bilinear discrete-time modeling for enhanced stability prediction and digital control design. Ieee T Power Electr 2003, 18, 381-389.

26. Li, X.; Ruan, X.; Jin, Q.; Sha, M.; Tse, C.K., Approximate Discrete-Time Modeling of DC-DC Converters with Consideration of the Effects of Pulse-Width Modulation. Ieee T Power Electr 2018, 33, (8), 7071-7082.

27. Leng, M.; Zhou, G.; Zhou, S.; Zhang, K.; Xu, S., Stability Analysis for Peak Current-Mode Controlled Buck LED Driver Based on Discrete-Time Modeling. Ieee J Em Sel Top P 2018, 6, (3), 1567-1580. 